Available online at www.eccomasproceedia.org

Eccomas Proceedia EUROGEN (2021) 35-41

ECCOMAS

Proceedia
EUROGEN 2021

$14^{\text {th }}$ ECCOMAS Thematic Conference on Evolutionary and Deterministic Methods for Design, Optimization and Control N. Gauger, K. Giannakoglou, M. Papadrakakis, J. Periaux (eds.) Streamed from Athens, Greece, 28-30 June 2021

\title{
A NEW MODIFIED JAYA ALGORITHM FOR OPTIMUM DESIGN OF TUNED MASS DAMPERS
}

\author{
Sinan Melih Nigdeli ${ }^{1}$ and Gebrail Bekdaş ${ }^{1}$ \\ ${ }^{1}$ Department of Civil Engineering, Istanbul University - Cerrahpaşa \\ Avc1lar, Istanbul, Turkey \\ e-mail: melihnig@istanbul.edu.tr, bekdas@istanbul.edu.tr
}

\begin{abstract}
Jaya algorithm (JA) is a metaheuristic algorithm that is very simple to use because of its simple features. One of these simple features is the use of a single phase of optimization. Second$l y$, by the advantage of existing of a single-phase, it is a parameter-free algorithm since a switch probability is not needed to select the optimization phase. However, it is a single-phase algorithm, it uses both existing best and worst solutions in the update of candidate solutions. In the first version of JA, the best and worst solutions are considered with the same weight by multiplying with random numbers. In this study, a modified JA is proposed to include the consideration of different weights for best and worst solutions. To not to be dependent on the parameters and to avoid always decreasing or increasing weight coefficients for the solutions, it is adjusted with a sine wave function that is updated via the iteration number. By this modification, it is possible to consider an active weight coefficient for both factors. The modified JA using sine wave is applied to the tuned mass damper (TMD) optimization problem that reduces the displacement of structures subjected to earthquake excitations. In the optimization process, the stroke limitation of TMD is also considered and the optimization is done for a wide set of earthquake records. The results of the proposed since wave Jaya (SJA) and JA are compared in means of convergence to the optimum results.
\end{abstract}

Keywords: Structural Optimization, Jaya Algorithm, Optimization, Metaheuristic Algorithms, Tuned Mass Damper 


\section{INTRODUCTION}

Jaya Algorithm (JA) is a metaheuristic algorithm that was first presented by Rao [1] as a single-phase algorithm that is different from the other algorithm generally having two optimization phases. Like the previously developed Teaching-learning-based optimization by Rao et al. [2], it is also a user-defined parameter-free algorithm, but only a phase is used instead of two phases such as teaching and learning phases of TLBO. Although JA has a single phase, both existing best and worst solutions are used together to provide convergence to the best solution, while it diverges from the worst one.

JA has been applied to many structural optimization problems by using several modifications. Kayabekir et al. [3] employed JA in the optimization of the amount of carbon fiberreinforced polymer (CFRP) that is used to increase the shear capacity of reinforced concrete (RC) beams. Dede [4] optimized steel grillage structures by using JA that minimize the weight of the structure constrained based on LRFD-AISC. Dinh-Cong et al. [5] used JA for damage assessment in plate-like structures. Degertekin et al. [6] developed a JA-based optimization method for sizing, layout, and topology optimization of truss structures. Artar and Daloglu [8] optimized seismic excited steel space towers with JA. Maksym et al. [9] employed JA for optimization of mass of braced dome structures with natural frequency constraints. Khatir et al. [10] combined JA and Artificial Neural Network (ANNs) to investigate crack identification in plates. Atmaca et al. [11] used JA in the optimization of a single pylon cable-stayed bridge that has cable size and pre-stressing force as design variables. Öztürk et al. [12] optimized RC counterfort retaining walls by using JA and TLBO. Kaveh et al [13] optimized skeletal structure with discrete variables by improving JA to escape local optima problem. Degertekin et al. [14] conducted layout optimization under natural frequency constraints via JA. Y1lmaz et al. [15] optimized RC retaining walls under static and dynamic loads via JA. Rakıc1 et al. optimized RC frame structures via JA [16]. Kayabekir et al. [17] investigated the optimization of RC T-beams via JA.

JA was also used in the optimization of structural control system includes tuned mass dampers (TMDs) [17-18], active tendon control system using proportional -integral- derivative (PID) controllers [19-20] and fuzzy controllers [21].

In the present study, an improved JA is presented and tested on the tuning of TMDs. The improvement is done to change the weight of best and worst solutions in the formulation of JA. A sine wave is defined to give dynamically changing weights for each iteration.

\section{SINE-WAVE JAYA ALGORITHM (SJA)}

Jaya means victory in the Sanskrit language and it is victorious to reach the optimum value. The equation of JA is given in Eq. (1).

$$
\mathrm{x}_{\mathrm{i}}^{\mathrm{t}+1}=\mathrm{x}_{\mathrm{i}}^{\mathrm{t}}+\mathrm{r}_{1}\left(\mathrm{~g}^{*}-\left|\mathrm{x}_{\mathrm{i}}^{\mathrm{t}}\right|\right)-\mathrm{r}_{2}\left(\mathrm{~g}^{\mathrm{w}}-\left|\mathrm{x}_{\mathrm{i}}^{\mathrm{t}}\right|\right)
$$

$\mathrm{x}_{\mathrm{i}}^{\mathrm{t}}$ represents a set of design variables for the $\mathrm{i}^{\text {th }}$ individual of $\mathrm{t}^{\text {th }}$ iteration. $\mathrm{x}_{\mathrm{i}}^{\mathrm{t}+1}$ is found via using best $\left(\mathrm{g}^{*}\right)$ and worst $\left(\mathrm{g}^{\mathrm{w}}\right)$ solutions. Two random numbers are represented via $\mathrm{r}_{1}$ and $\mathrm{r}_{2}$.

In the classical form of $\mathrm{JA}, \mathrm{g}^{*}$ and $\mathrm{g}^{\mathrm{w}}$ have the weight, but it is multiplied with a number. Also, the weights are always the same for all iterations. For that reason, a sine-wave function is applied for the weights of best and worst solutions. After the modification, the equation of the proposed SJA is given in Eq. (2). The sine values must be calculated as radian.

$$
\mathrm{x}_{\mathrm{i}}^{\mathrm{t}+1}=\mathrm{x}_{\mathrm{i}}^{\mathrm{t}}+\mathrm{r}_{1}|\sin (\mathrm{t})|\left(\mathrm{g}^{*}-\left|\mathrm{x}_{\mathrm{i}}^{\mathrm{t}}\right|\right)-\mathrm{r}_{2}(1-|\sin (\mathrm{t})|)\left(\mathrm{g}^{\mathrm{w}}-\left|\mathrm{x}_{\mathrm{i}}^{\mathrm{t}}\right|\right)
$$


The flowchart of the optimization process is summarized in Fig. 1. The design constants, design variables, objective function and design constraints are given in Section 3. The response of structure was found via dynamic analysis in the time-domain in all iterations.

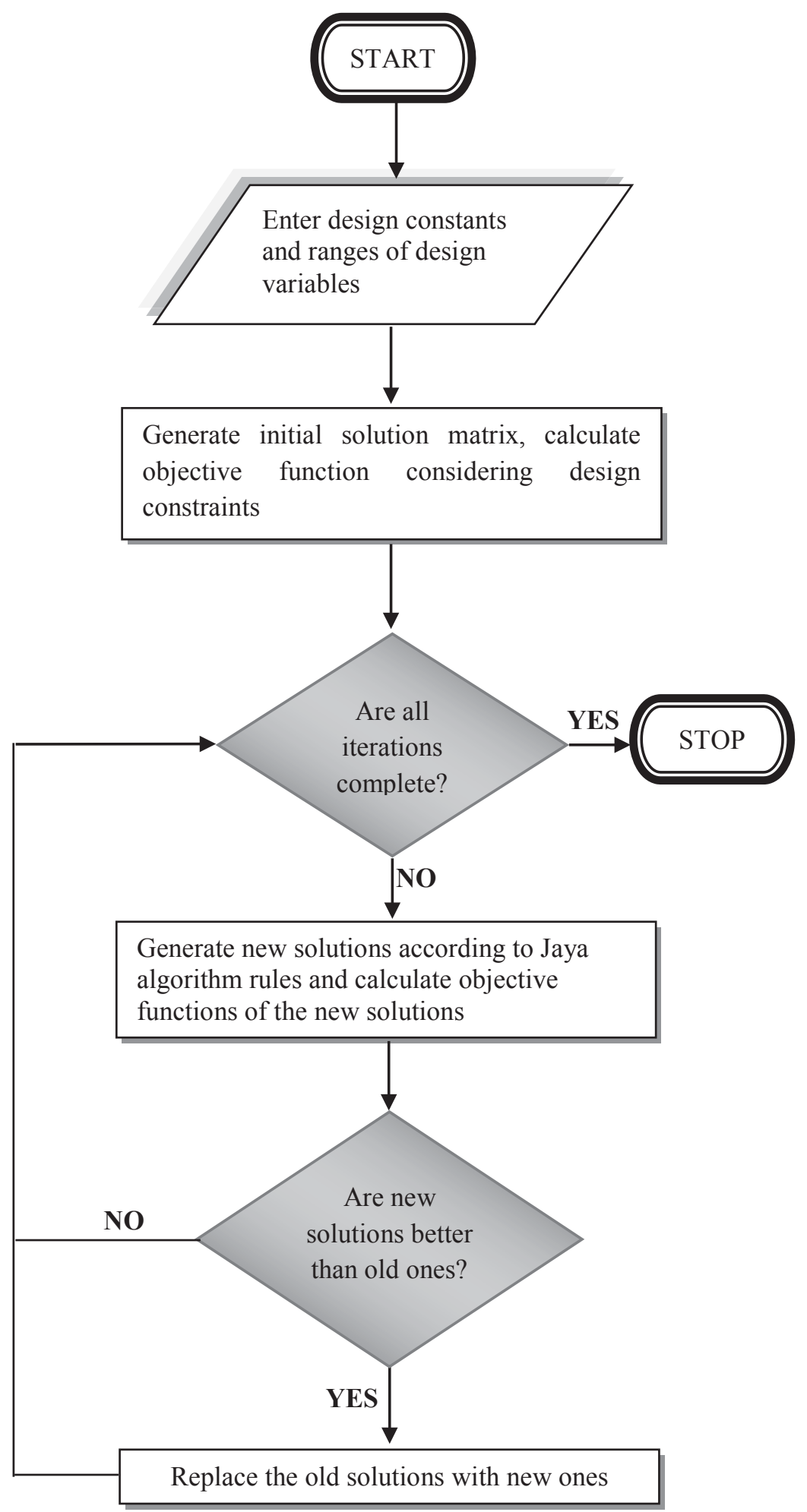

Figure 1: The flowchart of the optimization. 


\section{NUMERICAL EXAMPLES}

The design constants and the ranges of design variables are given in Table 1 for a 10-story shear building [23]. The structure was subjected to 44 ground motions that are defined as farfield ground motions in FEMA P-695: Quantification of Building Seismic Performance Factors [24].

Table 1: The design constants and variables

\begin{tabular}{|l|l|l|l|}
\hline Type & Symbol & Definition & Value \\
\hline \multirow{5}{*}{ Constant } & $\mathrm{m}_{\mathrm{i}}$ & Mass of $\mathrm{i}^{\text {th }}$ story & $360 \mathrm{t}$ \\
\cline { 2 - 4 } & $\mathrm{k}_{\mathrm{i}}$ & Stiffness of $\mathrm{i}^{\text {th }}$ story & $650 \mathrm{MN} / \mathrm{m}$ \\
\cline { 2 - 4 } & $\mathrm{c}_{\mathrm{i}}$ & Damping coefficient of $\mathrm{i}^{\text {th }}$ story & $6.2 \mathrm{MNs} / \mathrm{m}$ \\
\cline { 2 - 4 } & $\mathrm{m}_{\mathrm{d}}$ & Mass of TMD & $180 \mathrm{t}$ \\
\hline \multirow{2}{*}{ Variable } & $\mathrm{T}_{\mathrm{d}}$ & Period of TMD & $0.5 \mathrm{~s}-1.5 \mathrm{~s}$ \\
\cline { 2 - 4 } & $\xi_{\mathrm{d}}$ & Damping ratio of TMD & $1 \%-50 \%$ \\
\hline
\end{tabular}

The objective function of the problem is the minimization of top story displacement $\left(\mathrm{x}_{10}\right)$ of the structure as seen in Eq. (3). It is obtained by solving the equation of motion (Eq. (4)) that includes mass $(\mathrm{M})$, stiffness $(\mathrm{K})$, damping $(\mathrm{C})$ matrices, a vector ones $(\{1\})$ and ground acceleration $\ddot{x}_{\mathrm{g}} \cdot \mathrm{x}(\mathrm{t})$ defines the response of the structure.

$$
\begin{gathered}
\mathrm{f}(\mathrm{x})=\operatorname{minimize}\left(\left|\mathrm{x}_{10}\right|\right) \\
\mathrm{M} \ddot{\mathrm{x}}(\mathrm{t})+\mathrm{C} \dot{\mathrm{x}}(\mathrm{t})+\mathrm{Kx}(\mathrm{t})=-\mathrm{M}\{1\} \ddot{\mathrm{x}}_{\mathrm{g}}(\mathrm{t})
\end{gathered}
$$

The optimization problem is also constrained with the function $\left(\mathrm{g}_{1}\right)$ given as Eq. (5). It is a normalized stroke capacity of the TMD to limit its movement. It must be smaller than a userdefined value called stmax.

$$
\mathrm{g}_{1}=\frac{\max \left(\left|\mathrm{x}_{\mathrm{d}}-\mathrm{x}_{10}\right|\right)_{\text {withTMD }}}{\max \left(\left|\mathrm{x}_{10}\right|\right)_{\text {withoutTMD }}}<\text { st_max }
$$

$\mathrm{x}_{\mathrm{d}}$ is the displacement of TMD with respect to the ground. The design variables are formulated in Eqs. (6) and (7) with respect to mass $\left(\mathrm{m}_{\mathrm{d}}\right)$, stiffness $\left(\mathrm{k}_{\mathrm{d}}\right)$ and damping coefficient $\left(\mathrm{c}_{\mathrm{d}}\right)$ of TMD.

$$
\begin{aligned}
& \mathrm{T}_{\mathrm{d}}=2 \pi \sqrt{\frac{\mathrm{m}_{\mathrm{d}}}{\mathrm{k}_{\mathrm{d}}}} \\
& \xi_{\mathrm{d}}=\frac{\mathrm{c}_{\mathrm{d}}}{2 \mathrm{~m}_{\mathrm{d}} \sqrt{\frac{\mathrm{k}_{\mathrm{d}}}{\mathrm{m}_{\mathrm{d}}}}}
\end{aligned}
$$

In the optimization, the classical version of JA and SJA algorithm were compared. 100 maximum number of iterations are conducted and 10 cycles of optimization are applied. stmax is taken as 1 . The population number which defines the number of sets of design variables is taken as 5 . 


\section{RESULTS AND CONCLUSIONS}

The maximum displacement of the top story of the structure is $0.410109 \mathrm{~m}$ and it is obtained under the BOL090 component of the Bolu record of 1999 Düzce, Turkey earthquake. The optimum results of JA and SJA are given in Table 2.

Table 2: The optimum results

\begin{tabular}{|l|l|l|}
\hline & JA & SJA \\
\hline $\mathrm{T}_{\mathrm{d}}(\mathrm{s})$ & 0.904560044 & 0.902517645 \\
\hline$\xi_{\mathrm{d}}$ & 0.283683914 & 0.282289564 \\
\hline $\mathrm{f}(\mathrm{x})($ best $)(\mathrm{m})$ & 0.320240847 & 0.320235126 \\
\hline $\mathrm{f}(\mathrm{x})($ ave $)(\mathrm{m})$ & 0.323361718 & 0.322733436 \\
\hline std & 0.004388982 & 0.003896575 \\
\hline iteration & 38 & 21 \\
\hline
\end{tabular}

According to the results, JA and SJA are both effective to reduce the maximum top story displacement by $22 \%$. SJA has a slightly smaller objective function, but it has a significantly smaller average and standard deviation (std) value than JA. Also, it is possible to find the optimum solution in the $21^{\text {th }}$ iteration, while JA needs more iterations to reach the final value. The convergence plot for the optimization is presented in Fig. 2. Although JA has a good convergence at the start of the optimization process, SJA quickly converges to the final value.

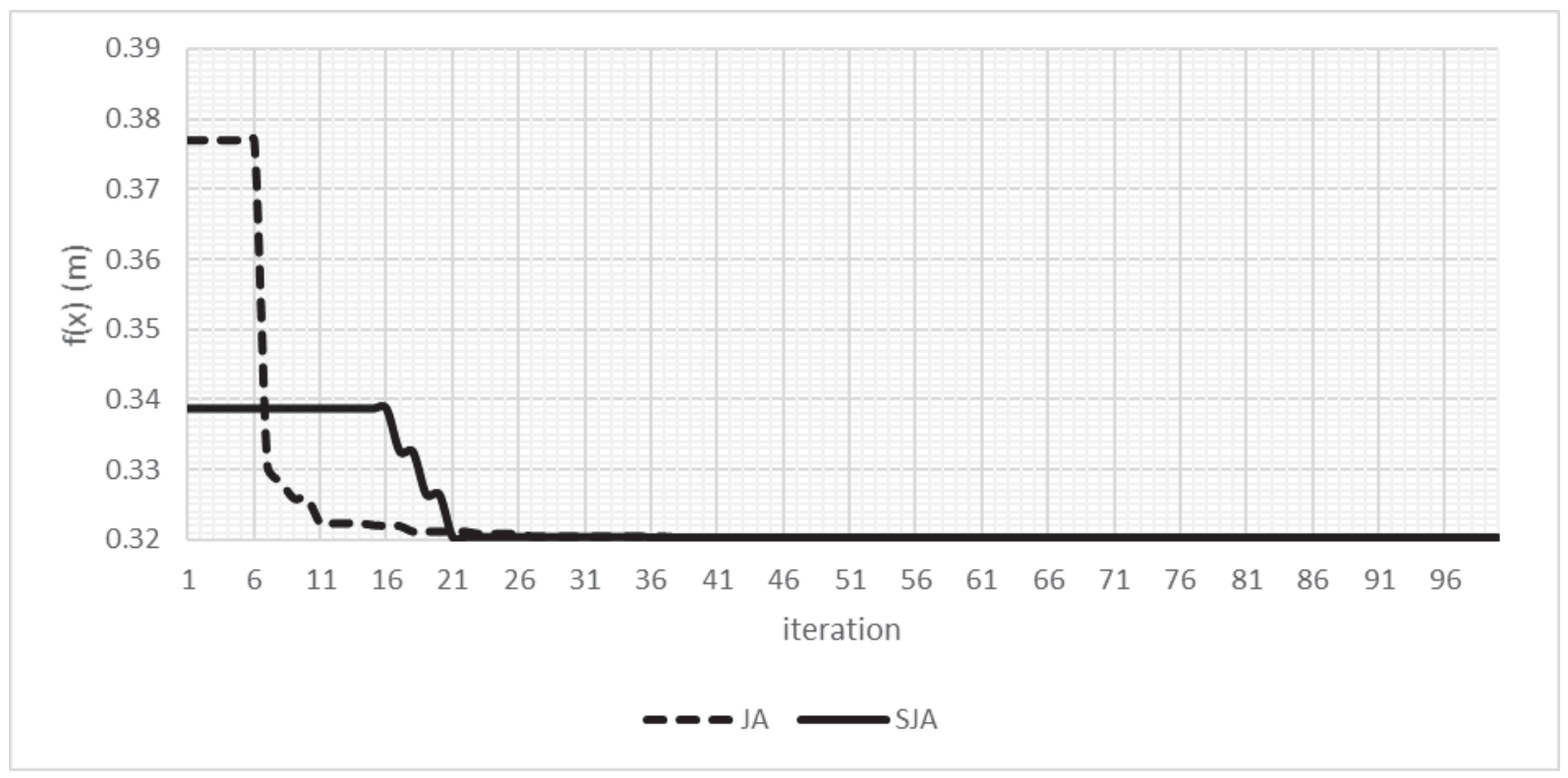

Figure 2: The convergence plot.

\section{REFERENCES}

[1] Rao, R. (2016). Jaya: A simple and new optimization algorithm for solving constrained and unconstrained optimization problems. International Journal of Industrial Engineering Computations, 7(1), 19-34. 
[2] Rao, R. V., Savsani, V. J., \& Vakharia, D. P. (2011). Teaching-learning-based optimization: a novel method for constrained mechanical design optimization problems. Computer-Aided Design, 43(3), 303-315.

[3] Kayabekir, A. E., Sayın, B., Nigdeli, S. M., \& Bekdaş, G. (2018, July). Jaya algorithm based optimum carbon fiber reinforced polymer design for reinforced concrete beams. In AIP Conference Proceedings (Vol. 1978, No. 1, p. 260006). AIP Publishing LLC.

[4] Dede, T. (2018). Jaya algorithm to solve single objective size optimization problem for steel grillage structures. Steel and Composite Structures, 26(2), 163-170.

[5] Dinh-Cong, D., Vo-Duy, T., Ho-Huu, V., \& Nguyen-Thoi, T. (2019). Damage assessment in plate-like structures using a two-stage method based on modal strain energy change and Jaya algorithm. Inverse Problems in Science and Engineering, 27(2), 166189.

[6] Degertekin, S. O., Lamberti, L., \& Ugur, I. B. (2018). Sizing, layout and topology design optimization of truss structures using the Jaya algorithm. Applied soft computing, 70, 903-928.

[7] Degertekin, S. O., Lamberti, L., \& Ugur, I. B. (2019). Discrete sizing/layout/topology optimization of truss structures with an advanced Jaya algorithm. Applied Soft Computing, 79, 363-390.

[8] Artar, M., \& Daloglu, A. T. (2019). Optimum design of steel space truss towers under seismic effect using Jaya algorithm. Structural Engineering and Mechanics, 71(1), 1-12.

[9] Grzywinski, M., Dede, T., \& Ozdemir, Y. I. (2019). Optimization of the braced dome structures by using Jaya algorithm with frequency constraints. Steel and Composite Structures, 30(1), 47-55.

[10] Khatir, S., Boutchicha, D., Le Thanh, C., Tran-Ngoc, H., Nguyen, T. N., \& AbdelWahab, M. (2020). Improved ANN technique combined with Jaya algorithm for crack identification in plates using XIGA and experimental analysis. Theoretical and Applied Fracture Mechanics, 107, 102554.

[11] Atmaca, B., Dede, T., \& Grzywinski, M. (2020). Optimization of cables size and prestressing force for a single pylon cable-stayed bridge with Jaya algorithm. Steel and Composite Structures, 34(6), 853-862.

[12] Öztürk, H. T., Dede, T., \& Türker, E. (2020, June). Optimum design of reinforced concrete counterfort retaining walls using TLBO, Jaya algorithm. In Structures (Vol. 25, pp. 285-296). Elsevier.

[13] Kaveh, A., Hosseini, S. M., \& Zaerreza, A. (2021, February). Improved Shuffled Jaya algorithm for sizing optimization of skeletal structures with discrete variables. In Structures (Vol. 29, pp. 107-128). Elsevier.

[14] Degertekin, S. O., Bayar, G. Y., \& Lamberti, L. (2021). Parameter free Jaya algorithm for truss sizing-layout optimization under natural frequency constraints. Computers \& Structures, 245, 106461.

[15] Yılmaz, N., Aral, S., Nigdeli, S. M., \& Bekdaş, G. (2020, April). Optimum Design of Reinforced Concrete Retaining Walls Under Static and Dynamic Loads Using Jaya Algorithm. In International Conference on Harmony Search Algorithm (pp. 187-196). Springer, Singapore. 
[16] Rakıcı, E., Bekdaş, G., \& Nigdeli, S. M. (2020, April). Optimal Cost Design of SingleStory Reinforced Concrete Frames Using Jaya Algorithm. In International Conference on Harmony Search Algorithm (pp. 179-186). Springer, Singapore.

[17] Kayabekir, A. E., Bekdaş, G., \& Nigdeli, S. M. (2019). Optimum design of T-beams using Jaya algorithm. In 3rd International Conference on Engineering Technology and Innovation (ICETI), Belgrad, Serbia.

[18] Bekdaş, G., Kayabekir, A. E., Nigdeli, S. M., \& Toklu, Y. C. (2019). Tranfer function amplitude minimization for structures with tuned mass dampers considering soilstructure interaction. Soil Dynamics and Earthquake Engineering, 116, 552-562.

[19] Kayabekir, A. E., Bekdaş, G., Nigdeli, S.M. (2020). Active Tuned Mass Dampers for Control of Seismic Structures. WSEAS Transactions on Computers, 19, 122-128.

[20] Ulusoy, S., Bekdas, G., \& Nigdeli, S. M. (2020). Active structural control via metaheuristic algorithms considering soil-structure interaction. Structural Engineering and Mechanics, 75(2), 175-191.

[21] Ulusoy, S., Nigdeli, S. M., \& Bekdaş, G. (2021). Novel metaheuristic-based tuning of PID controllers for seismic structures and verification of robustness. Journal of Building Engineering, 33, 101647.

[22] Azizi, M., Ghasemi, S. A. M., Ejlali, R. G., \& Talatahari, S. (2020). Optimum design of fuzzy controller using hybrid ant lion optimizer and Jaya algorithm. Artificial Intelligence Review, 53(3), 1553-1584.

[23] M.P. Singh, S. Singh, L.M. Moreschi, Tuned mass dampers for response control of torsional buildings, Earthq. Eng. Struct. D. 31 (2002) 749-769.

[24] FEMA P-695, Quantification of Building Seismic Performance Factors, Federal Emergency Management Agency, Washington DC, 2009. 